\title{
Structure Development in a Thermoplastic Polyimide. Cold Crystallization as Revealed by Microhardness
}

\author{
Maria Esperanza Cagiao, Marco Connor, ${ }^{\dagger}$ Francisco Jose Baltá Calleja, ${ }^{\dagger \dagger}$ \\ and James C. Seferis*
}
Instituto de Estructura de la Materia, CSIC, Serranol19, 28006 Madrid, Spain
* PCL, Department of Chemical Engineering, University of Washington, Box 351750, Seattle, Washington 98195-1750, U.S.A.

(Received October 1, 1998)

\begin{abstract}
The isothermal "cold crystallization" of the thermoplastic polyimide (New TPI) has been studied using the microhardness technique to examine the property-microstructure correlation. By using wide- and small-angle X-ray diffraction and differential scanning calorimetry, the influence of the experimental parameters, i.e., treatment temperature $T_{\mathrm{c}}$ and time $t_{\mathrm{c}}$ on the micromechanical properties of the "cold crystallized" samples has been examined. It is shown that both macroscopic hardness $H$ and volume crystallinity $x_{\mathrm{c}}$ increase with $T_{\mathrm{c}}$ and $t_{\mathrm{c}}$. For the samples prepared in the secondary crystallization range, it is demonstrated that $H$ values strongly depend on the hardness of the crystalline units $H_{\mathrm{c}}$. In this range, long spacing $L$, crystal thickness $l_{\mathrm{c}}$ and crystallinity (both linear $x_{\mathrm{CL}}$, and derived from density $x_{\mathrm{c}}$ ) slightly increase with $T_{\mathrm{c}}$. From the DSC study, it is demonstrated that the proportion of "liquid-like" and "rigid" amorphous fraction present in each sample is directly related with the crystallization conditions. Finally, from the SAXS and DSC combined study, information concerning the secondary crystallization mechanism has been obtained.
\end{abstract}

KEY WORDS Thermoplastic Polyimide / Microhardness / Crystallinity / "Liquid-Like" and "Rigid"

Amorphous Fraction /

Aromatic polyimides have many technological applications, mainly due to their specific chemical structure. The presence of aromatic and imide rings in the monomeric units imparts rigidity to the polymeric chain. As a result, aromatic polyimides exhibit high $T_{\mathrm{g}}$ (glass transition temperature) and $T_{\mathrm{m}}$ (melting temperature) values. Besides good thermal stability, these materials show excellent mechanical and electrical properties and high radiation and solvent resistance. Aromatic polyimides are therefore widely used in specific applications: electronic packaging for printed circuits, insulation for lead wire, etc, being particularly useful in the aerospace industry.

Some specific products of this group, e.g., the so called Kapton (developed by DuPont de Nemours Company) and BTDA-ODA based polyimide (obtained from benzophenone tetracarboxylic dianhydride and 4,4'-oxydianiline) have very rigid chains, being for this reason extremely difficult to melt-process and crystallize. To overcome this inconvenience, synthetic methods have been developed in order to lower the transition temperatures by different routes: incorporation of substitutes in the aromatic rings, introduction of more flexible groups $\left(\left(-\mathrm{CH}_{2}-\right)_{n},-\mathrm{O}-\right)$ or meta-phenyl linkages into the main chain, ${ }^{2,2}$ etc. The thermoplastic polyimide has been synthesized using the last route. Its monomeric unit contains both ether groups and phenyl rings substituted in meta-position. ${ }^{3}$. The result is a crystallizable material with a glass transition temperature $T_{\mathrm{g}}$ of about $250^{\circ} \mathrm{C}$. This value is notably lower than those exhibited by other aromatic polyimides. For this reason, the crystallization of New TPI can be easily followed from the molten ${ }^{3}$ or from the amorphous solid state ("cold crystallization"). ${ }^{4}$ The dynamic crystallization of New TPI as it is cooled from the melt can also be easily studied. ${ }^{5}$ In all cases, a semicrystalline polymer with a melting point $T_{\mathrm{m}}$ of about $380^{\circ} \mathrm{C}$ is obtained. This polyimide presents excellent mechanical properties, high-temperature stability, solvent resistance and melt processability. 6,7

The structure and properties of New TPI have been reported by several research groups. ${ }^{3-15}$ Thus, the crystalline structure has been studied by means of the wide-angle X-ray scattering. ${ }^{8}$ The spherulitic morphology has been examined by using transmission electron microscopy, ${ }^{9}$ and optical microscopy. ${ }^{3}$ Other researchers have investigated the rheological ${ }^{10}$ and thermal properties ${ }^{11}$ of this material. Data concerning the crystal lattice thermal expansion behavior ${ }^{12}$ of $\mathrm{New}$ TPI have also been reported. Some authors have investigated the stability of this polyimide against radiation, ${ }^{7,13}$ whereas others have studied its dielectric and dynamic mechanical relaxation. ${ }^{14}$ The crystallization kinetics from the molten state has been investigated by Hsiao, Sauer, and Biswas, ${ }^{3}$ and the isothermal cold crystallization kinetics by Huo, Friler, and Cebe. ${ }^{4} \mathrm{Lu}$, Cebe, and Capel $^{15}$ have used real time small-angle X-ray scattering (SAXS) and thermally stimulated depolarization currents (TSDC) to study the structural characteristics and relaxation behavior of New TPI. In addition, the dynamic crystallization, while cooling from the melt, was modelled by Seferis and Deshpande ${ }^{5}$ through the incorporation of induction time considerations into the Avrami kinetics. It was also found that TPI experiences a loss of "crystallizability" after exposure to multiple processing cycles or extended times at temperatures above the melt. This was attributed to loss of nucleation sites. $^{5}$

The aim of the present study is to extend the above

\footnotetext{
$\dagger$ Permanent address: EMS-Chemie AG, CH-7013 Domat/Ems, Switzerland.

${ }^{\dagger \dagger}$ To whom correspondence should be addressed.
} 
investigation to examine the structure-microhardness correlation of New TPI. Due to its simplicity, the microhardness technique has become a widely used method for measuring the mechanical properties of polymers. ${ }^{16-20}$. Furthermore, the microhardness is a property sensitive to morphological and structural changes in polymers. ${ }^{18,19}$ In particular, the microhardness of glassy polymers has been shown to be affected by the changes occurring in the morphology as a result of the crystallization from the glassy state. ${ }^{21,22}$ Hence, we think that the microhardness could be applied to the study of the structure development of New TPI after crystallization using calorimetric and X-ray scattering methods.

This work forms part of a wider research project directed to clarify the crystallization mechanism underlying the higher-order structures of crystalline polymers. $^{23}$

\section{EXPERIMENTAL}

New TPI polyimide has been developed by Mitsui Chemical Co. (formerly Mitsui Toatsu Chemical Co.). The samples used in this study were transparent, amorphous, 80 and $200 \mu \mathrm{m}$ thick films. The amorphous samples were "cold crystallized" by annealing them at the temperatures and times indicated in Table I. The thermal treatment was carried out in a Linkam heating device. It is noteworthy that no other treatment was performed on the films before the "cold crystallization" process.

Density was measured at $23^{\circ} \mathrm{C}$ by a density gradient column filled with a carbon tetrachloride- $n$-hexane mixture. Volume crystallinity values $x_{\mathrm{c}}$ were derived from the density $\rho$ data by using the expression:

$$
x_{\mathrm{c}}=\left(\rho-\rho_{\mathrm{a}}\right) /\left(\rho_{\mathrm{c}}-\rho_{\mathrm{a}}\right)
$$

assuming for the density of the crystals a value $\rho_{\mathrm{c}}=$ $1.467 \mathrm{~g} \mathrm{~cm}^{-38}$ and for the amorphous density a value $\rho_{\mathrm{a}}=1.328 \mathrm{~g} \mathrm{~cm}^{-3}$ (calculated in this work).

Wide-angle X-ray scattering (WAXS) patterns were obtained in the reflection mode using a Rigaku-Denki goniometer. A rotating anode X-ray generator using $\mathrm{Ni}$-filtered $\mathrm{Cu}-K_{\alpha}$ radiation working at $40 \mathrm{KV}$ and 140 $\mathrm{mA}$ was used. The SAXS patterns were obtained with a point collimation Rigaku camera (sample to film distance $=300 \mathrm{~mm}$ ) and, in some cases, with a point collimation Kiessig camera (sample to film distance $=$ $500 \mathrm{~mm}$ ). Ni-filtered $\mathrm{Cu}-K_{\alpha}$ radiation from a $40 \mathrm{kV}$, $70 \mathrm{~mA}$ source was used. The long spacings $(L)$ were obtained from the SAXS patterns by directly applying the Bragg's law to the diffraction maxima of the various samples.

The samples were analyzed by differential scanning calorimetry (DSC) using a Perkin-Elmer DSC 7 model. The sample weight was $3.5-5 \mathrm{mg}$, being the heating rate $20^{\circ} \mathrm{C} \mathrm{min}^{-1}$. All scans were performed in a $\mathrm{N}_{2}$ atmosphere.

Microhardness $(H)$ was measured at room temperature using a Leitz tester adapted with a square-based diamond indenter with included angles $\alpha$ between non adjacent faces of the pyramid of $136^{\circ}$. The $H$ value was derived from the residual projected area of indentation according
Table I. Preparation conditions of New TPI samples

\begin{tabular}{|c|c|c|c|c|c|c|c|c|c|c|c|}
\hline$\frac{T_{\mathrm{c}}}{{ }^{\mathrm{C}}}$ & 270 & 280 & 310 & 320 & 330 & & & & & & \\
\hline$\frac{t_{\mathrm{c}}}{\min }$ & 0 & 3 & 5 & 10 & 15 & 30 & 45 & 60 & 90 & 120 & 180 \\
\hline
\end{tabular}

\section{New TPI}

$\mathrm{T}_{\mathrm{c}}=320^{\circ} \mathrm{C}$

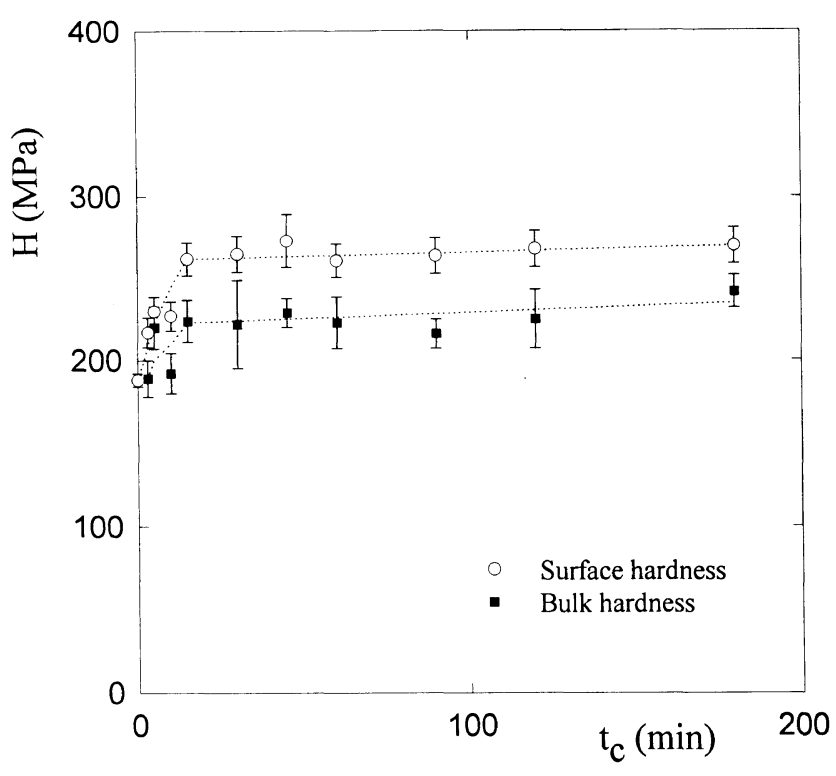

Figure 1. Surface (open symbols) and bulk (filled symbols) microhardness as a function of crystallization time $t_{\mathrm{c}}$ for samples of New TPI "cold crystallized" at $T_{\mathrm{c}}=320^{\circ} \mathrm{C}$.

to the expresion $H=k P / d^{2}$ (MPa), where $d$ is the length of the impression diagonal in meters, $P$ is the contact load applied in $\mathrm{N}$ and $k$ is a geometrical factor equal to 1.854. A loading cycle of $0.1 \mathrm{~min}$ and loads of $0.15,0.25$, and $1 N$ were used. Preliminary hardness measurements were performed at the surface and in the interior of the samples. It was found that the surface layer of the TPI samples was harder than the bulk (see Figure 1). In what follows, we shall refer our results to microhardness measurements performed on the samples surface.

\section{RESULTS}

\section{Microhardness Studies}

The studied samples were crystallized from the glassy state for different times at different temperatures (see Table I). To discuss the results obtained we shall distinguish between two morphologies: i) Structures obtained by interrupting the primary crystallization (the growth of spherulites is not completed), ii) Structures in which the growth of spherulites is completed, obtained by crystallization at different temperatures beyond the end of the primary crystallization.

Figure 2 shows the initial gradual increase (from an initial value $H_{\mathrm{a}}=185 \mathrm{MPa}$, corresponding to the amorphous TPI) and the final leveling off in $H$ as a function of the crystallization time $t_{\mathrm{c}}$ for the various tem- 


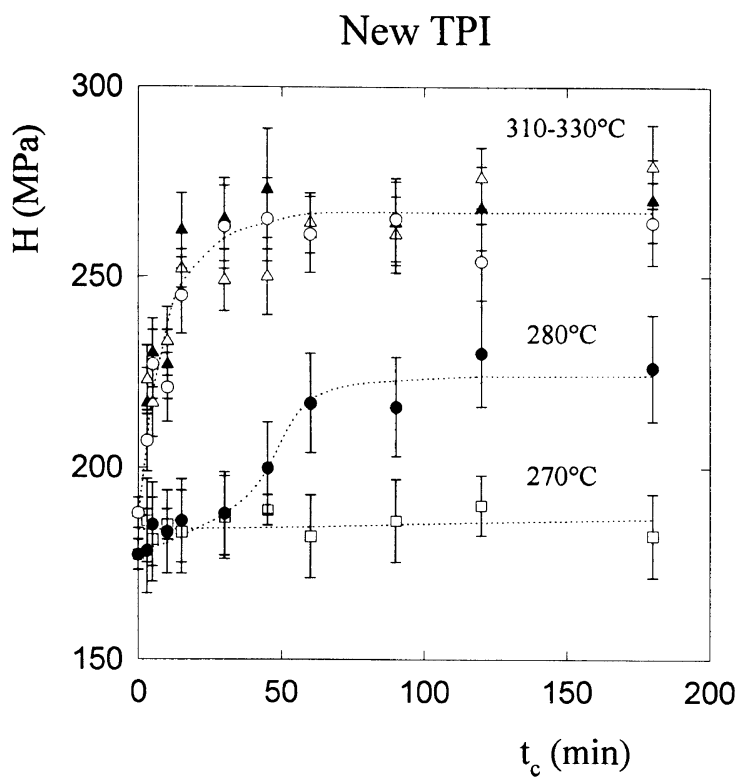

Figure 2. Surface hardness $v$ s. crystallization time $t_{\mathrm{c}}$ of New TPI "cold crystallized" for various crystallization temperatures $T_{\mathrm{c}}$.

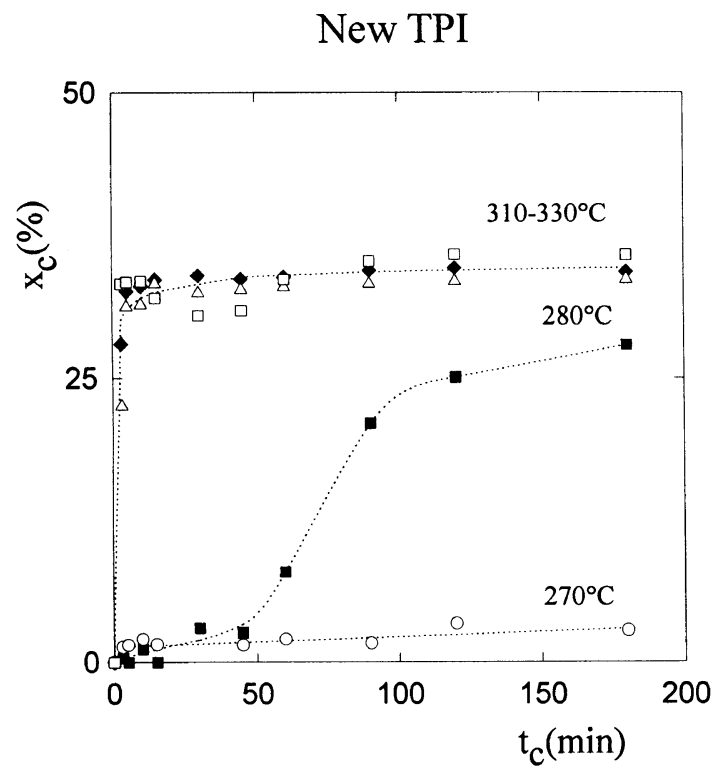

Figure 3. Degree of crystallinity $x_{\mathrm{c}}$ (derived from density) of New TPI "cold crystallized" at various temperatures $T_{\mathrm{c}}$ as a function of the crystallization time $t_{\mathrm{c}}$.

peratures $T_{\mathrm{c}}$.

In order to obtain samples in which the growth of spherulites is not completed, we have crystallized amorphous New TPI at 270 and $280^{\circ} \mathrm{C}$ for different times. At $T_{\mathrm{c}}=270^{\circ} \mathrm{C}$ the hardening process is very slow with a negligible $H$ variation. However, the $H$ increase for $T_{\mathrm{c}}=280^{\circ} \mathrm{C}$ shows two well defined regions: a first faster raise until $t_{\mathrm{c}} \cong 60 \mathrm{~min}$, and then a much slower $H$ increase up to values of $220 \mathrm{MPa}$ for $t_{\mathrm{c}} \cong 180 \mathrm{~min}$. In the range $T_{\mathrm{c}}=310-330^{\circ} \mathrm{C}$, the hardness increases very quickly until $t_{\mathrm{c}}=15 \mathrm{~min}$ and then it levels off to final values between 264 and $279 \mathrm{MPa}$. We have represented the $H-t_{\mathrm{c}}$ variation for the three highest temperatures by a unique curve for the sake of clarity. The hardness increase observed for each crystallization temperature is correlated with the development of crystallinity as shown in

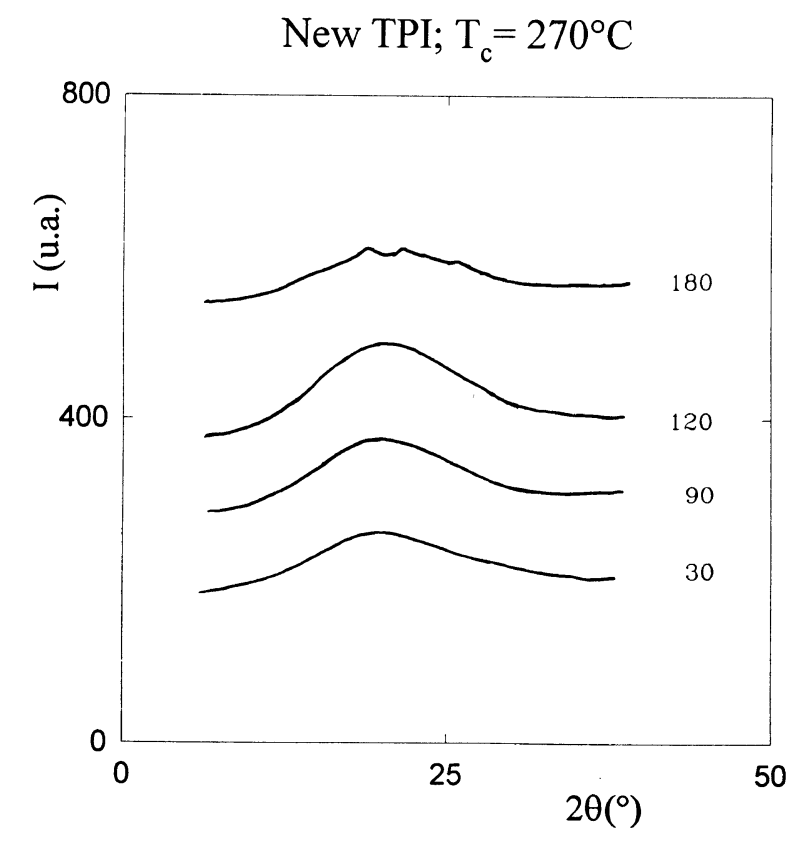

(a)

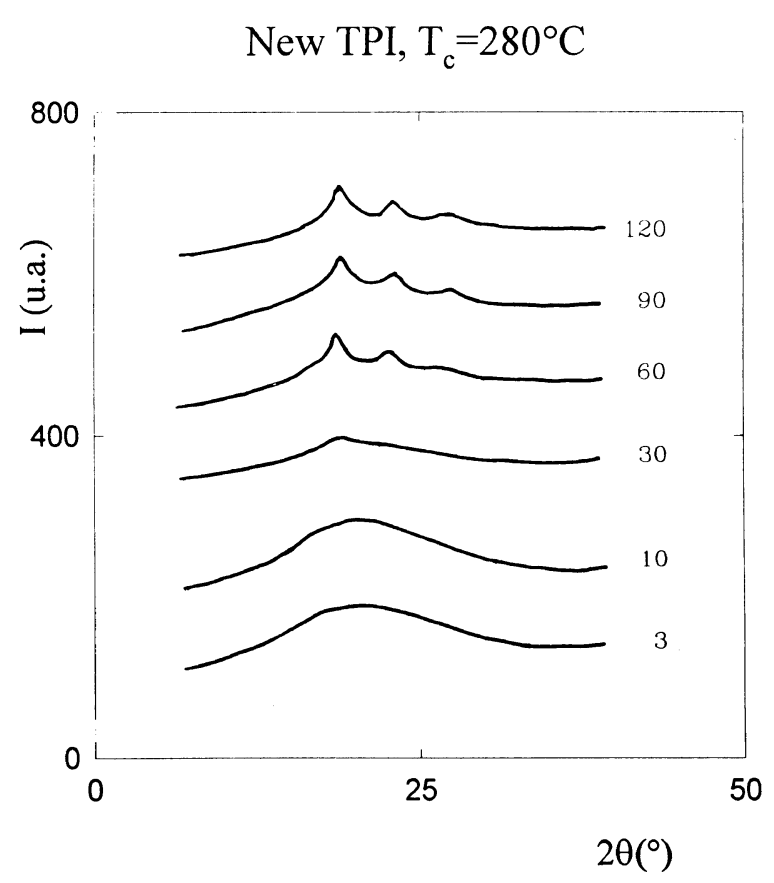

(b)

Figure 4. Evolution of the WAXS diagrams for New TPI samples crystallized at (a) $270^{\circ} \mathrm{C}$ and (b) $280^{\circ} \mathrm{C}$ during different crystallization times $t_{\mathrm{c}}$. Beside each diagram, $t_{\mathrm{c}}$ in minutes is indicated.

Figure 3. Here the degree of crystallinity $x_{\mathrm{c}}$ determined from density is plotted as a function of time for various temperatures. As it can be seen, $x_{\mathrm{c}}$ values of $33-36 \%$ are reached at the end of the crystallization for the higher temperatures. It is noteworthy that for the almost negligible increase in $H$ at $T_{\mathrm{c}}=270^{\circ} \mathrm{C}$ (Figure 2) a very small crystallinity value $x_{\mathrm{c}} \cong 3 \%$ is observed.

Figure 4 illustrates the structure evolution as a function of time for $T_{\mathrm{c}}=270$ and $280^{\circ} \mathrm{C}$ respectively by WAXS. In the case of the samples crystallized at $T_{\mathrm{c}}=270^{\circ} \mathrm{C}$, the appearance of very faint crystalline reflexions is observed only for $t_{\mathrm{c}} \geq 180 \mathrm{~min}$ (Figure 4a). At $T_{\mathrm{c}}=280^{\circ} \mathrm{C}$ the crystalline reflections start appearing for $t_{\mathrm{c}} \geq 30 \mathrm{~min}$ 
Table II. Crystallinity values obtained from density data, $x_{\mathrm{c}}$, and from WAXS, $x_{\mathrm{c}}^{\mathrm{RX}}$, in New TPI samples "cold crystallized" at $T_{\mathrm{c}}=330^{\circ} \mathrm{C}$

\begin{tabular}{rll}
$t_{\mathrm{c}} / \min$ & $x_{\mathrm{c}} / \%$ & $x_{\mathrm{c}}^{\mathrm{RX}} / \%$ \\
\hline 15 & 32.0 & 21.7 \\
60 & 33.6 & 22.1 \\
90 & 35.2 & 23.6 \\
120 & 35.8 & 24.3 \\
180 & 35.8 & 23.3
\end{tabular}

Table III. Crystalline fraction, $x_{c}$, "liquid-like" amorphous fraction $x_{\mathrm{a}}$, and "rigid" amorphous fraction $x_{\mathrm{ra}}$ in New TPI samples crystallized at different temperatures $T_{\mathrm{c}}$

\begin{tabular}{ccccccc}
\hline$T_{\mathrm{c}} /{ }^{\circ} \mathrm{C}$ & $x_{\mathrm{c}}{ }^{\mathrm{a}}$ & $x_{\mathrm{a}}{ }^{\mathrm{a}}$ & $x_{\mathrm{ra}}{ }^{\mathrm{a}}$ & $x_{\mathrm{c}}{ }^{\mathrm{b}}$ & $x_{\mathrm{a}}{ }^{\mathrm{b}}$ & $x_{\mathrm{ra}}{ }^{\mathrm{b}}$ \\
\hline 310 & 0.31 & 0.40 & 0.29 & 0.24 & 0.61 & 0.15 \\
320 & 0.33 & 0.38 & 0.29 & 0.25 & 0.62 & 0.13 \\
330 & 0.34 & 0.38 & 0.28 & 0.26 & 0.62 & 0.12
\end{tabular}

${ }^{\mathrm{a}}$ This work; $t_{\mathrm{c}}=10 \mathrm{~min} .{ }^{\mathrm{b}} \mathrm{Huo}$, Friler, and $\mathrm{Cebe}^{4} ; t_{\mathrm{c}}=10 \mathrm{~min}$.

Table IV. Long spacing, $L$, crystal thickness, $l_{\mathrm{c}}$, and amorphous phase thickness, $L-l_{\mathrm{c}}$ evolution with crystallization time $t_{\mathrm{c}}$ in New TPI samples "cold crystallized" at $T_{\mathrm{c}}=310,320$, and $330^{\circ} \mathrm{C}$

\begin{tabular}{|c|c|c|c|c|c|c|c|c|c|}
\hline \multirow{2}{*}{$t_{\mathrm{c}} \mathrm{min}$} & \multicolumn{3}{|c|}{$310^{\circ} \mathrm{C}$} & \multicolumn{3}{|c|}{$320^{\circ} \mathrm{C}$} & \multicolumn{3}{|c|}{$330^{\circ} \mathrm{C}$} \\
\hline & $L / \AA$ & $l_{\mathrm{c}} / \AA$ & $L-l_{\mathrm{c}} / \AA$ & $L / \AA$ & $l_{\mathrm{c}} / \AA$ & $L-l_{\mathrm{c}} / \AA$ & $L / \AA$ & $l_{\mathrm{c}} / \AA$ & $L-l_{\mathrm{c}} / \AA$ \\
\hline 3 & 206 & 76 & 130 & 213 & 99 & 114 & 214 & 114 & 100 \\
\hline 5 & 209 & 105 & 104 & 208 & 107 & 101 & 212 & 109 & 103 \\
\hline 10 & 203 & 105 & 98 & 207 & 110 & 97 & 210 & 112 & 98 \\
\hline 120 & 195 & 101 & 94 & 204 & 110 & 94 & 212 & 117 & 95 \\
\hline
\end{tabular}

(Figure 4b). For the samples crystallized at $T_{\mathrm{c}} \geq 310^{\circ} \mathrm{C}$ the crystalline peaks appear immediately.

The crystallinity values obtained from WAXS were calculated by dividing the area of the crystalline peaks by the total diffracted area, and are $\sim 30 \%$ lower than those derived from density data. Table II illustrates comparatively both sets of values for New TPI samples crystallized at $330^{\circ} \mathrm{C}$. One possible explanation for this difference has been discussed in terms of the role played by the interface located at the lamellar surface. ${ }^{14.15,24}$

\section{Calorimetry and Microstructure (Rigid Amorphous Frac-} tion)

From the DSC study, the heat-capacity increment $\Delta C_{\mathrm{p}}$ at $T_{\mathrm{g}}$ for each sample was measured, and from these data the "liquid-like" amorphous fraction, $x_{\mathrm{a}}$, and "rigid" amorphous fraction, $x_{\text {ra }}$, values have been derived. The mobile or "liquid-like" amorphous fraction is defined as the fraction of the amorphous phase that undergoes a distinct heat-capacity jump at $T_{\mathrm{g}}$, similar to the one observed with purely amorphous sample. ${ }^{4}$ The value of $x_{\mathrm{a}}$ is defined as:

$$
x_{\mathrm{a}}=\Delta C_{\mathrm{p}} / \Delta C_{\mathrm{p}}^{\mathrm{a}}
$$

where $\Delta C_{\mathrm{p}}^{\mathrm{a}}$ is the heat-capacity increment of a $100 \%$ amorphous sample. The "rigid" amorphous fraction, $x_{\mathrm{ra}}$, is originated by the constraint of crystal lamellae on amorphous chains in the semicrystalline samples. ${ }^{4}$ The $x_{\mathrm{ra}}$ value is derived from ${ }^{25,4}$ :

$$
x_{\mathrm{ra}}=1-x_{\mathrm{c}}-x_{\mathrm{a}}
$$

Table III illustrates the comparison between the $x_{c}$, $x_{\mathrm{a}}$, and $x_{\mathrm{ra}}$ values found in this work, and those reported by Huo, Friler, and Cebe. ${ }^{4}$ It is important to note that these researchers have obtained the $x_{\mathrm{c}}, x_{\mathrm{a}}$, and $x_{\mathrm{ra}}$ data from the calorimetric study, and used $\Delta H_{\mathrm{m}}^{\infty}=139$ $\mathrm{Jg}^{-14,25}$ as the heat of fusion of a $100 \%$ crystalline sample to calculate the $x_{\mathrm{c}}$ fraction. However, our $x_{\mathrm{c}}$ values have been obtained from density data. Both series of values are considerably different, particularly those of $x_{\mathrm{a}}$ and $x_{\mathrm{ra}}$ fractions. This is probably due to the fact

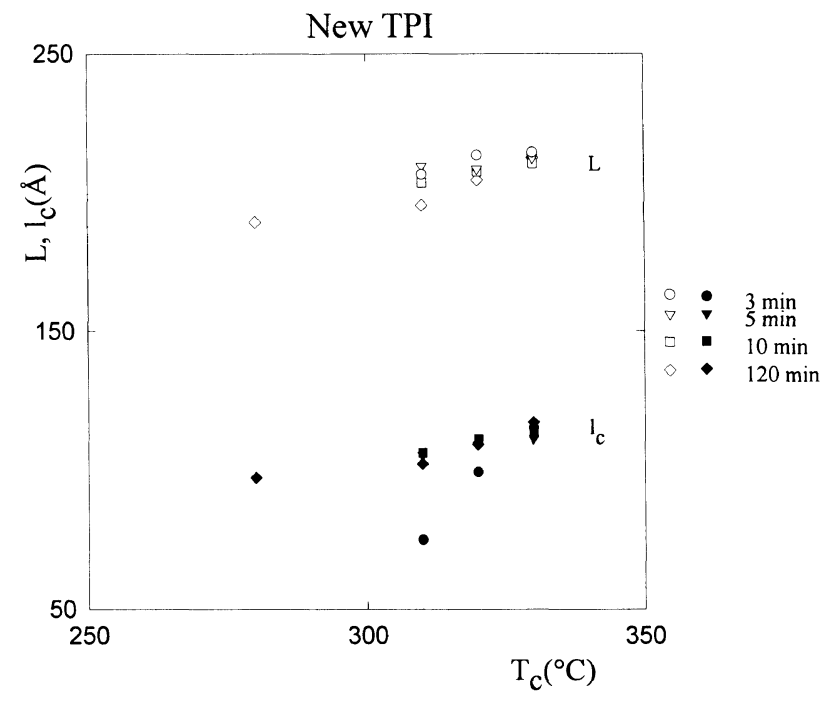

Figure 5. Long spacing $L$ (open symbols) and average crystal thickness $l_{\mathrm{c}}$ (filled symbols) derived from SAXS and DSC for New TPI samples "cold crystallized" for different times $t_{\mathrm{c}}$, as functions of crystallization temperature $T_{\mathrm{c}}$.

that our samples have been only subjected to a "cold crystallization" process, whereas the samples studied by Huo et al. ${ }^{4}$ were previously dried $\left(150^{\circ} \mathrm{C}, 20 \mathrm{~h}\right)$, and finally relaxed $\left(260^{\circ} \mathrm{C}, 20 \mathrm{~h}\right)$. Therefore, a possible explanation for this discrepancy could be the lower molecular mobility in our samples as compared to those studied by Huo et al.

For a given temperature, the long spacing $L$ slowly decreases as a function of treatment time $t_{\mathrm{c}}$ (see Table IV). The crystal thickness $l_{\mathrm{c}}$, derived from

$$
l_{\mathrm{c}}=x_{\mathrm{c}} L /\left(1-x_{\mathrm{a}}\right)
$$

increases very quickly during the first $5 \mathrm{~min}$ and then levels off. Table IV shows the $L$ and $l_{\mathrm{c}}$ evolution with $t_{\mathrm{c}}$ for the samples crystallized at 310,320 , and $330^{\circ} \mathrm{C}$. Figure 5 shows the variation of both long spacing $L$ and crystal thickness $l_{\mathrm{c}}$ with the crystallization temperature $T_{\mathrm{c}}$. The thickness, $L-l_{c}$, of the amorphous phase is nearly 
New TPI

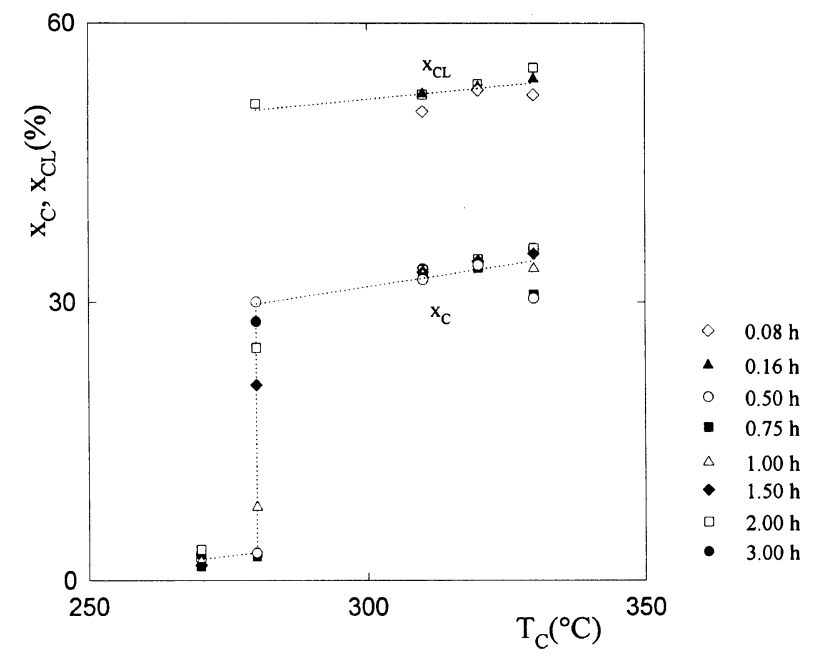

Figure 6. Linear crystallinity $x_{\mathrm{CL}}=l_{\mathrm{c}} / L$, derived from SAXS and DSC, and crystallinity $x_{\mathrm{c}}$ derived from density, for New TPI samples isothermally crystallized from the glassy state for different times $t_{\mathrm{c}}$ as a function of $T_{\mathrm{c}}$.

Table V. Thermal properties of New TPI samples "cold crystallized" at $T_{\mathrm{c}}=320^{\circ} \mathrm{C}$ for different times $t_{\mathrm{c}}$

\begin{tabular}{|c|c|c|c|c|c|}
\hline$t_{\mathrm{c}}$ & $T_{\mathrm{g}}$ & $\Delta C_{\mathrm{p}}$ & $x_{\mathrm{a}}$ & $T_{\mathrm{m}}$ & $\Delta H_{\mathrm{m}}$ \\
\hline $\min$ & ${ }^{\circ} \mathrm{C}$ & $\mathrm{Jg} \mathrm{K}^{-1}$ & $\%$ & ${ }^{\circ} \mathrm{C}$ & $\mathrm{Jg}^{-1}$ \\
\hline 3 & 245.3 & 0.12 & 40 & $\begin{array}{l}325.2 \\
382.5\end{array}$ & 37.50 \\
\hline 5 & 244.3 & 0.12 & 38 & $\begin{array}{l}323.7 \\
382.6\end{array}$ & 38.45 \\
\hline 10 & 245.8 & 0.12 & 38 & $\begin{array}{l}327.7 \\
382.8\end{array}$ & 39.11 \\
\hline 120 & 245.3 & 0.11 & 35 & $\begin{array}{l}330.4 \\
381.8\end{array}$ & 41.51 \\
\hline
\end{tabular}

$T_{\mathrm{g}}$ and $T_{\mathrm{m}}$, glass transition and melting temperatures; $\Delta C_{\mathrm{p}}$, heat-capacity increment at $T_{\mathfrak{g}} ; x_{\mathrm{a}}$, "liquid-like" amorphous fraction derived from the $\Delta C_{\mathrm{p}}$ data (see the text); $\Delta H_{\mathrm{m}}$, total melting enthalpy calculated for both $T_{\mathrm{m} 1}$ and $T_{\mathrm{m} 2}$ peaks.

independent of $T_{\mathrm{c}}$ for long treatment times $t_{\mathrm{c}}$ (see Table IV).

In Figure 6 it can be seen that both the volume crystallinity, $x_{c}$, (see eq 1) and the linear crystallinity, $x_{\mathbf{C L}}$, defined as:

$$
x_{\mathrm{CL}}=l_{\mathrm{c}} / L
$$

show a similar dependence on $T_{\mathrm{c}}$.

The DSC heating scans of most isothermally crystallized specimens exhibit two distinct maxima $T_{\mathrm{ml}}$ and $T_{\mathrm{m} 2}$. The former value $T_{\mathrm{m} 1}$ occurred from 3 to 13 degrees above $T_{\mathrm{c}}$ and the latter, $T_{\mathrm{m} 2}$, was nearly independent of $t_{\mathrm{c}}$ and $T_{\mathrm{c}}$. Table $\mathrm{V}$ lists the calorimetric data of samples crystallized at $T_{\mathrm{c}}=320^{\circ} \mathrm{C}$, being $\Delta H_{\mathrm{m}}$ the total melting enthalpy calculated for both peaks, $T_{\mathrm{m} 1}$ and $T_{\mathrm{m} 2}$. This double melting behavior can be explained by the reorganization model. The first melting peak comes from the crystals present in the sample at room temperature, before the scan takes place. These crystals are very imperfect, and melt just above the cold crystallization temperature, giving rise to the first peak at $T_{\mathrm{m} 1}$. After a recrystallization reorganization process,

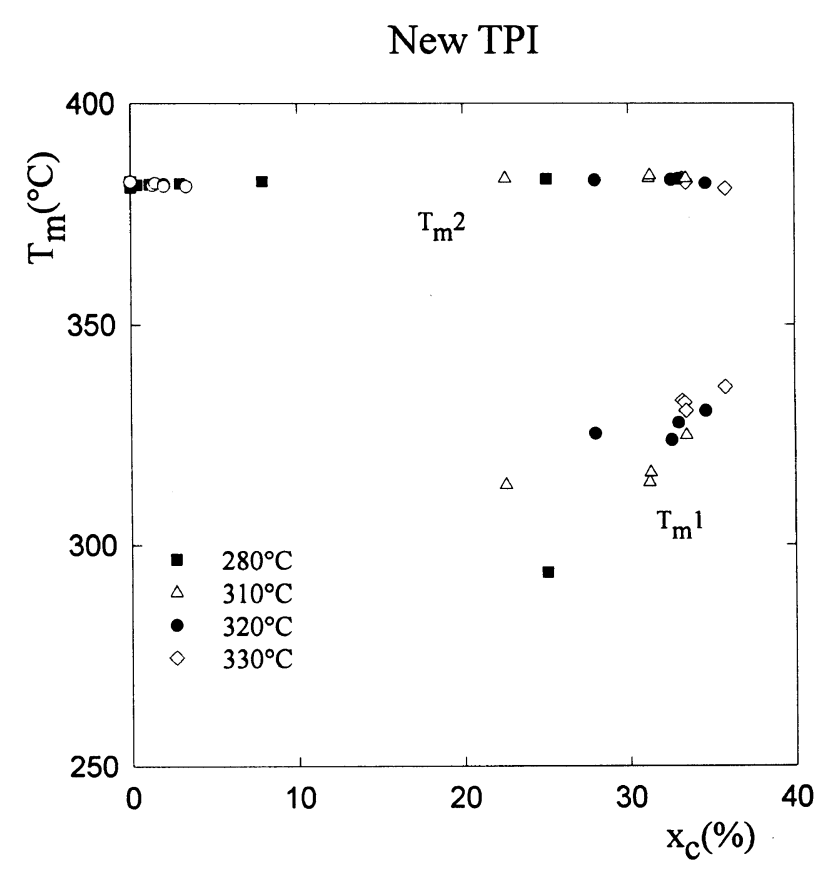

Figure 7. Plot of the upper $T_{\mathrm{m} 2}$ and lower $T_{\mathrm{m} 1}$ melting peak temperature as a function of the crystallinity degree $x_{\mathrm{c}}$ (derived from density), for New TPI samples isothermally crystallized from the glassy state at different temperatures $T_{\mathrm{c}}$ and for different times $t_{\mathrm{c}}$.

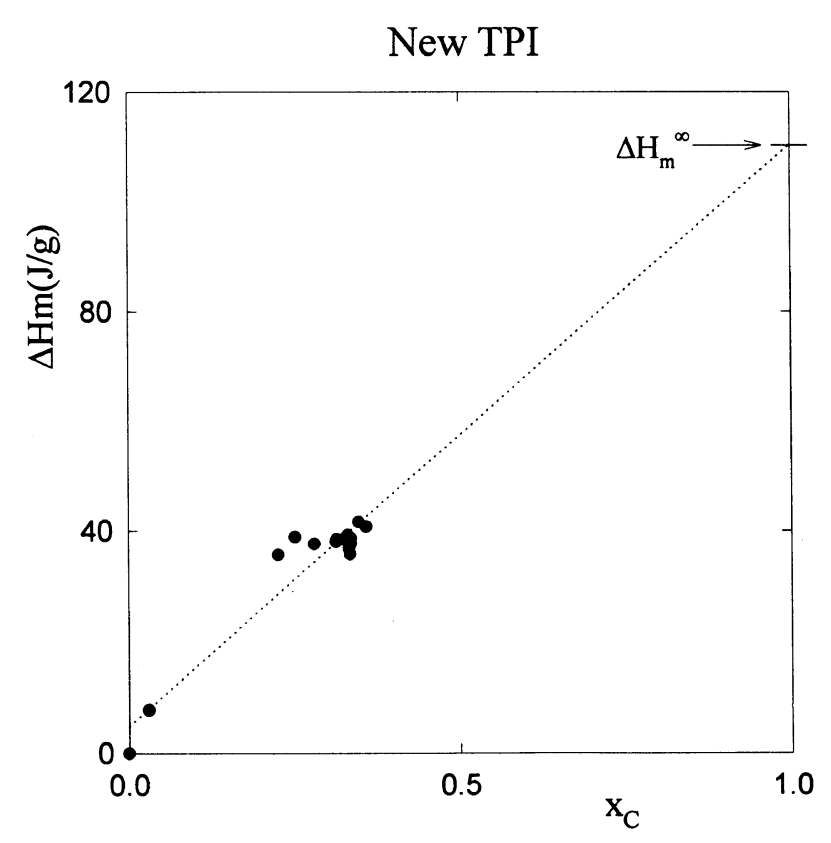

Figure 8. Heat of fusion $\Delta H_{\mathrm{m}}$ as a function of density $\rho$ for New TPI "cold crystallized" at different temperatures $T_{\mathrm{c}}$ and for different times $t_{\mathrm{c}}$.

they eventually melt again at $T_{\mathrm{m} 2} \cdot{ }^{4}$ It can be clearly seen in Figure 7 that $T_{\mathrm{m} 1}$ increases with $x_{\mathrm{c}}$, whereas $T_{\mathrm{m} 2}$ remains practically constant. This result, together with the $L$ and $l_{\mathrm{c}}$ variation with $t_{\mathrm{c}}$ (see Table IV) favors the crystal insertion model, i.e., secondary crystalline structures grow between the primary lamellae as crystallization proceeds. ${ }^{3}$

The linear relationship between the heat of fusion $\Delta H_{\mathrm{m}}$ and the crystallinity $x_{\mathrm{c}}$, for samples crystallized at different temperatures for different times (Figure 8), after extrapolation to $x_{\mathrm{c}}=1$, yields for the heat of fusion of a $100 \%$ crystalline sample, $\Delta H_{\mathrm{m}}^{\infty}=110 \mathrm{~J} \mathrm{~g}^{-1}$. This value is 
Table VI. New TPI samples "cold crystallized" at $T_{\mathrm{c}}=310,320$, and $330^{\circ} \mathrm{C}$ for different times $t_{\mathrm{c}}$

\begin{tabular}{|c|c|c|c|c|c|c|}
\hline \multirow{2}{*}{$t_{\mathrm{c}} / \min$} & \multicolumn{2}{|c|}{$310^{\circ} \mathrm{C}$} & \multicolumn{2}{|c|}{$320^{\circ} \mathrm{C}$} & \multicolumn{2}{|c|}{$330^{\circ} \mathrm{C}$} \\
\hline & $x_{\mathrm{c}}$ & $x_{\mathrm{c}}^{\mathrm{DSC}}$ & $x_{\mathrm{c}}$ & $x_{\mathrm{c}}^{\mathrm{DSC}}$ & $x_{\mathrm{c}}$ & $x_{\mathrm{c}}^{\mathrm{DSC}}$ \\
\hline 3 & 22.6 & 32.3 & 28.0 & 34.1 & 33.2 & 33.3 \\
\hline 5 & 31.2 & 34.4 & 32.6 & 35.0 & 33.4 & 32.4 \\
\hline 10 & 31.3 & 34.8 & 33.0 & 35.6 & 33.5 & 35.0 \\
\hline 120 & 33.5 & 34.2 & 34.6 & 37.7 & 35.8 & 36.9 \\
\hline
\end{tabular}

Comparison between $x_{\mathrm{c}}$, crystallinity derived from density data, and $x_{\mathrm{c}}^{\mathrm{DSC}}$, crystallinity obtained from the calorimetric study, using the value $\Delta H_{\mathrm{m}}=110 \mathrm{~J} \mathrm{~g}^{-1}$ as the melting enthalpy for a $100 \%$ crystalline sample (see the text).

Table VII. Surface free energy, $\sigma_{\mathrm{e}}$, calculated for New TPI samples "cold crystallized" at $T_{\mathrm{c}}=310$, 320 , and $330^{\circ} \mathrm{C}$ for different times $t_{\mathrm{c}}$

\begin{tabular}{rccc} 
& \multicolumn{3}{c}{$\sigma_{\mathrm{e}} / \mathrm{erg} \mathrm{cm}^{-2}$} \\
& $310_{\mathrm{c}} / \min \mathrm{C}$ & $320^{\circ} \mathrm{C}$ & $330^{\circ} \mathrm{C}$ \\
\cline { 2 - 4 } & 36 & 48 & 55 \\
5 & 50 & 52 & 53 \\
10 & 50 & 53 & 55 \\
120 & 48 & 53 & 59 \\
\hline
\end{tabular}

lower than the one reported by Mitsui Toatsu, ${ }^{26}$ $\Delta H_{\mathrm{m}}^{\infty}=139 \mathrm{~J} \mathrm{~g}^{-1}$, and in fair agreement with the data of Hsiao, Sauer, and Biswas, ${ }^{3} \Delta H_{\mathrm{m}}^{\infty}=116 \mathrm{~J} \mathrm{~g}^{-1}$, and Deshpande and Seferis, ${ }^{27} \Delta H_{\mathrm{m}}^{\infty}=112.5 \mathrm{Jg}^{-1}$. The crystallinity values $x_{\mathrm{c}}^{\text {DSC }}$ calculated from the melting enthalpy data by using our value $\Delta H_{\mathrm{m}}^{\infty}=110 \mathrm{~J} \mathrm{~g}^{-1}$ are very similar to the volume crystallinity data $x_{\mathrm{c}}$ derived from density measurements (see Table VI for comparison). Only in the samples treated at 310 and $320^{\circ} \mathrm{C}$ for 3 min a discrepancy between $x_{\mathrm{c}}$ and $x_{\mathrm{c}}^{\text {DSC }}$ values can be found, probably due to the crystallization of the material upon heating of the DSC. Therefore, we consider our $\Delta H_{\mathrm{m}}^{\infty}$ value to be correct. As it was above indicated, $T_{\mathrm{m} 2}$ is almost constant and does not depend on the crystal thickness $l_{c}$, as it was previously demonstrated by Hsiao, Sauer, and Biswas for samples crystallized at $T_{\mathrm{c}} \leq 320^{\circ} \mathrm{C}^{3}$ Therefore, if $\sigma_{\mathrm{e}}$ is defined as the surface free energy, the Thomson Gibbs equation:

$$
T_{\mathrm{m}}=T_{\mathrm{m}}^{0}\left[1-\left(2 \sigma_{\mathrm{e}} / \Delta H_{\mathrm{m}}^{\infty} l_{\mathrm{c}}\right)\right]
$$

cannot be applied to derive the $T_{\mathrm{m}}^{0}$ value (equilibrium melting temperature) from $T_{\mathrm{m}}$ and $l_{\mathrm{c}}$ data. Thus, the value $T_{\mathrm{m}}^{0}=424^{\circ} \mathrm{K}$ obtained by Lu et al. ${ }^{15}$ was used in eq 6 together with the value of $\Delta H_{\mathrm{m}}^{\infty}=110 \mathrm{~J} \mathrm{~g}^{-1}$ obtained in this study in order to calculate the surface free energy $\sigma_{\mathrm{e}}$. In this way $\sigma_{\mathrm{e}}$ values varying between 36 and 59 $\mathrm{erg} \mathrm{cm}{ }^{-2}$ were derived (see Table VII). These values are higher than the one reported by $\mathrm{Lu}, \mathrm{Cebe}$, and Capel, $\sigma_{\mathrm{e}}=41 \mathrm{erg} \mathrm{cm}^{-2} \cdot{ }^{15}$ During the first $3-5 \mathrm{~min}, \sigma_{\mathrm{e}}$ slightly increases, and then levels off. The highest $\sigma_{\mathrm{e}}$ values are obtained for the highest crystallization temperature $T_{\mathrm{c}}=$ $330^{\circ} \mathrm{C}$.

\section{DISCUSSION}

In the course of isothermal crystallization at and above

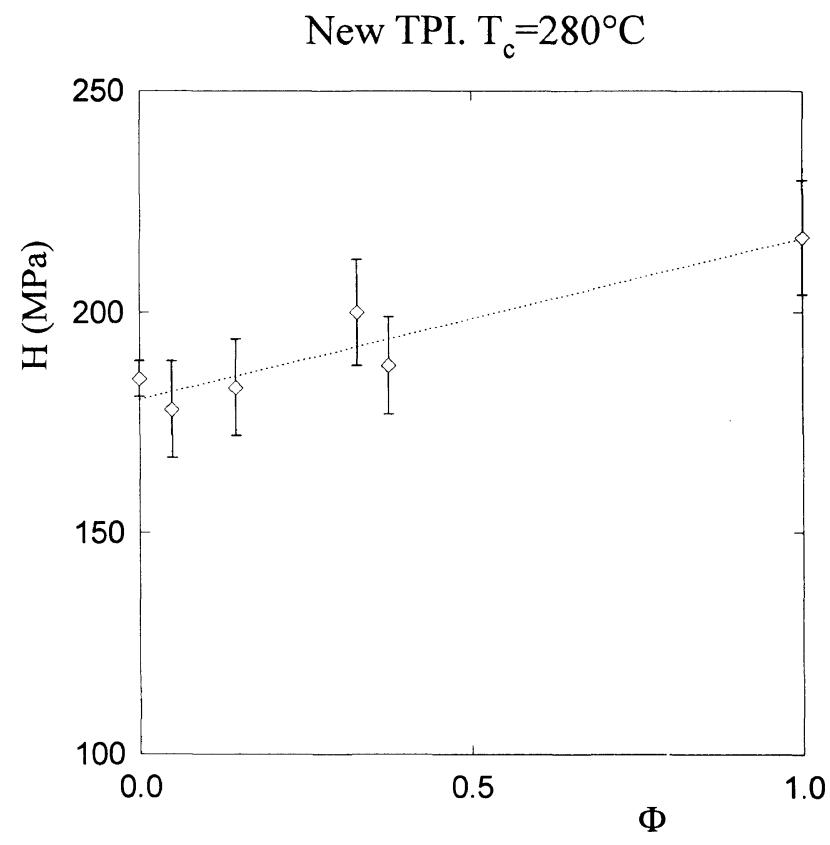

Figure 9. Plot of the macroscopic hardness $H$ as a function of the volume fraction of spherulites, $\Phi=\alpha / \alpha_{0}$.

$T_{\mathrm{c}}=280^{\circ} \mathrm{C}$ one observes first a rapid sigmoidal increase of the degree of crystallinity $x_{\mathrm{c}}$, followed by a very slow raise (Figure 3 ). The first rapid increase is associated to primary crystallization. The following much slower process is called secondary crystallization. ${ }^{28}$ During primary crystallization one often observes spherulites growing until they impinge to each other. ${ }^{28}$

It is noteworthy that the variation of $H$ during isothermal crystallization also shows the first rapid increase (Figure 2). However, in the region of secondary crystallization $H$ remains constant. This behavior is similar to that exhibited by poly(ethylene terephthalate) (PET) "cold crystallized" from the glassy amorphous state at $T_{\mathrm{c}}>120^{\circ} \mathrm{C} .{ }^{21}$ The cause for this discrepancy between $H$ and $x_{\mathrm{c}}$ in the secondary crystallization regime has to be sought in the mechanical behavior of the rigid amorphous regions constrained between the crystal lamellae. Let us assume that the yield process (microhardness) in the rigid amorphous regions is the same as in the crystalline lamellae. Then, after primary crystallization, when the spherulites fill up the samples completely, the $H$ value remains constant while the crystallinity increases due to the gradual crystallization of the amorphous interlamellar regions.

In the primary crystallization region the growth of spherulites is not completed and the expresion ${ }^{21}$ :

$$
H=H_{\mathrm{sph}} \Phi+H_{\mathrm{a}}(1-\Phi)
$$

can be used to calculate the hardness of the spherulitic material. In the above expresion $H_{\mathrm{a}}$ is the hardnesss of the amorphous glassy material and $\Phi=\alpha / \alpha_{0}{ }^{21}$ is the volume fraction of the spherulites, being $\alpha$ the crystallinity value after a time $t_{\mathrm{c}}$ and $\alpha_{0}$ the crystallinity at which $H$ levels off when the primary crystallization process is completed. Figure 9 shows the variation of $H$ as a function of $\Phi$ for $T_{\mathrm{c}}=280^{\circ} \mathrm{C}$. We have found that $H_{\text {sph }}$ varies between 215 and $230 \mathrm{MPa}$, increasing with $T_{\mathrm{c}}$.

In the second region (secondary crystallization) the 
Table VIII. Crystalline phase hardness, $H_{\mathrm{c}}$, and $b$ (measure of the hardness depression from $\Delta H_{\mathrm{c}}^{\infty}$, see the text), calculated for New

TPI samples "cold crystallized" at $T_{\mathrm{c}}=310,320$, and $330^{\circ} \mathrm{C}$ for different times $t_{\mathrm{c}}$

\begin{tabular}{rcccc}
\hline & \multicolumn{3}{c}{$H_{\mathrm{c}} / \mathrm{MPa}$} & \multirow{2}{*}{$b / \AA$} \\
\cline { 2 - 3 }$t_{\mathrm{c}} / \min$ & $310^{\circ} \mathrm{C}$ & $320^{\circ} \mathrm{C}$ & $330^{\circ} \mathrm{C}$ & \\
\hline 10 & 251 & 260 & 271 & 94 \\
120 & 334 & 339 & 348 & 46 \\
\hline
\end{tabular}

\section{New TPI}

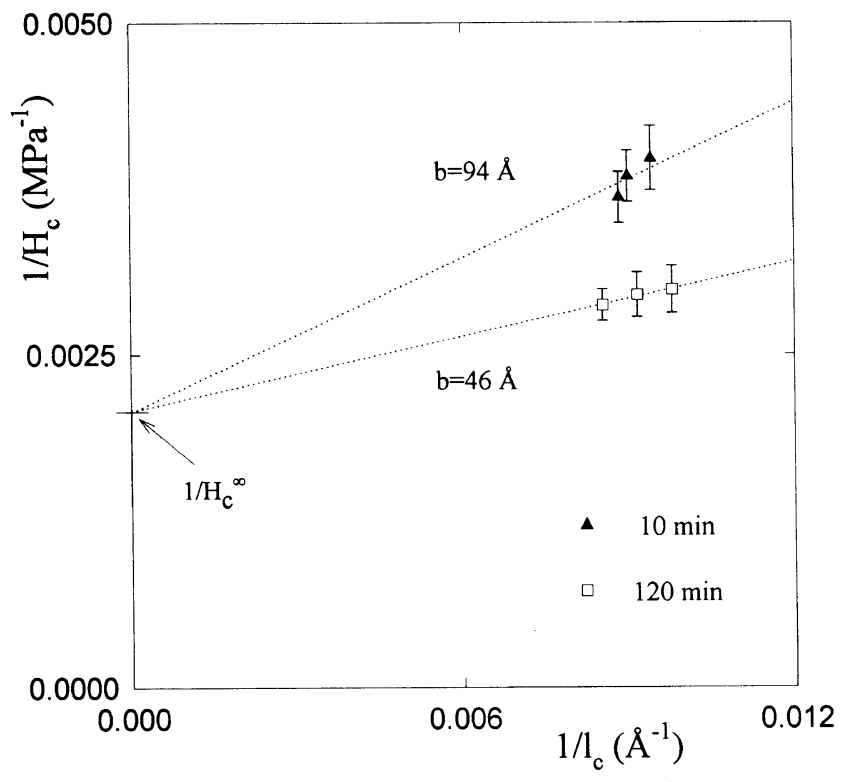

Figure 10. Plot of the reciprocal crystal hardness $1 / H_{\mathrm{c}}$ against the reciprocal crystal thickness $1 / l_{\mathrm{c}}$ for "cold crystallized" New TPI at $T_{\mathrm{c}}=310-330^{\circ} \mathrm{C}$

hardness additivity law for semicrystalline polymers ${ }^{29}$ :

$$
H_{\mathrm{sph}}=H_{\mathrm{c}} x_{\mathrm{CL}}+H_{\mathrm{a}}\left(1-x_{\mathrm{CL}}\right)
$$

applies. $x_{\mathrm{CL}}=l_{\mathrm{c}} / L$ is the linear crystallinity, as it was above defined. $H_{\mathrm{c}}$ and $H_{\mathrm{a}}$ are the hardness values for the crystalline and amorphous phase respectively. In this way, the hardness of the crystal lamellae $H_{\mathrm{c}}$ for each sample was derived (see Table VIII). It is also known that the relationship between $H_{\mathrm{c}}$ and $l_{\mathrm{c}}$ is given by ${ }^{30}$ :

$$
H_{\mathrm{c}}=H_{\mathrm{c}}^{\infty} /\left(1+b / l_{\mathrm{c}}\right)
$$

Figure 10 shows the plot $1 / H_{\mathrm{c}}$ versus $1 / l_{\mathrm{c}}$ for $t_{\mathrm{c}}=10$ and $120 \mathrm{~min}$. In this plot, $b / H_{\mathrm{c}}^{\infty}$ represents the slope of each straight line. $H_{\mathrm{c}}^{\infty}$ is the hardness of an infinitely large crystal. The $b$ parameter is a measure of the hardness depression from $H_{\mathrm{c}}^{\infty}$, and is equal to $2 \sigma_{\mathrm{e}} / \Delta h,{ }^{31}$ where $\sigma_{\mathrm{e}}$ is the surface free energy of the crystal lamellae and $\Delta h$ is the energy for crystal destruction. The $b$ value was found to decrease from 94 to $46 \AA$ when $t_{\mathrm{c}}$ increases from 10 to $120 \mathrm{~min}$ (Figure 10 and Table VIII). From the analysis of the results obtained in the characterization of the samples, it can be seen that, for samples prepared in the secondary crystallization range, the crystal thickness $l_{\mathrm{c}}$ increases only slightly with $T_{\mathrm{c}}$ and $t_{\mathrm{c}}$ (Table IV and Figure 5), and so does the linear crystallinity $x_{\mathrm{CL}}$
(Figure 6). These variations are not sufficient to explain the macroscopic hardness $H$ increase with both $T_{\mathrm{c}}$ and $t_{\text {c }}$. Contrary to the "cold crystallized" PET samples above cited, ${ }^{21}$ in Table VIII it can be clearly seen that in the TPI samples presented in this study the crystalline hardness $H_{\mathrm{c}}$ is strongly dependent on the treatment temperature and time. From these results, one can conclude that for semicrystalline New TPI "cold crystallized" samples, the macroscopic hardness $H$ depends mainly on the crystalline hardness $H_{\mathrm{c}}$, the latter being an increasing function of $T_{\mathrm{c}}$ and $t_{\mathrm{c}}$. The $H_{\mathrm{c}}$ increase with $t_{\mathrm{c}}$ could be explained by the decrease of the $b$ parameter from 94 to $46 \AA$ in going from $t_{\mathrm{c}}=10 \mathrm{~min}$ to $t_{\mathrm{c}}=120 \mathrm{~min}$ (see Figure 10 and Table VIII). As the surface free energy $\sigma_{\mathrm{e}}$ is almost constant for each temperature, the $b$ behavior could be related to the increasing perfection or higher degree of order of the crystals with $t_{\mathrm{c}}$, thus giving rise to higher values of the $\Delta h$ (energy for crystal destruction) as $t_{\mathrm{c}}$ increases.

\section{CONCLUSIONS}

- Cold crystallization of New TPI above $310^{\circ} \mathrm{C}$ yields a material with $H$ values near $270 \mathrm{MPa}$. This is one of the largest hardness values obtained for synthetic rigid polymers.

- From the microhardness study it seems clear that macroscopic hardness $H$ is strongly influenced by the hardness of the crystalline units $H_{\mathrm{c}}$, which is an increasing function of treatment temperature $T_{\mathrm{c}}$ and time $t_{\mathrm{c}}$.

- Data concerning the crystalline, "liquid-like" amorphous and "rigid" amorphous fraction have also been derived. From the evolution of the long spacing and crystal thickness during the thermal treatment, and from the melting behavior, we have concluded on the existence of secondary crystalline structures between the primary lamellae.

Acknowledgments. The authors are indebted to DGICYT (Grant PB94-0049), Madrid (Spain). We wish also to thank NEDO's International Joint Research Programme, Japan, for the generous support of this investigation. Partial financial support was provided by the Polymeric Composites Laboratory Consortium at the University of Washington.

\section{REFERENCES}

1. C. Arnold, Macromol. Rev., J. Polvm. Sci., 14, 265 (1979).

2. P. M. Hergenrother and S. J. Havens, J. Polym. Sci., 27, 1161 (1989).

3. B. S. Hsiao, B. B. Sauer, and A. Biswas, J. Polym. Sci., Part B, Polym. Phys., 32, 737 (1994).

4. P. P. Huo, J. B. Friler, and P. Cebe, Polymer, 34, 4387 (1993).

5. A. Deshpande, Doctoral Dissertation, University of Washington (1996).

6. J. B. Friler and P. Cebe, Polym. Eng. Sci., 33, 587 (1993).

7. T. Sasuga, Polymer, 32, 1539 (1991).

8. K. Okuyama, H. Sakaitani, and H. Arikawa, Macromolecules, 25, 7261 (1992).

9. T. Takahashi, S. Yuasa, M. Tsuji, and K. Sakurai, J. Macromol. Sci., Phys., B33, 63 (1994).

10. T. H. Hou and R. M. Reddy, SAMPE Q., 22, 38 (1991).

11. M. V. Brillhart and P. Cebe, J. Polym. Sci., Part B, Polym. Phys., 33, 927 (1995) 
12. S. X. Lu, P. Cebe, and M. Capel, Polymer, 37, 2999 (1996).

13. T. Hirade, Y. Hama, T. Sasuga, and T. Seguchi, Polymer, 32, 2499 (1991)

14. P. P. Huo and P. Cebe, Polymer, 34, 696 (1993).

15. S. X. Lu, P. Cebe, and M. Capel, J. Appl. Polym. Sci., 57, 1359 (1995).

16. B. Darlix, B. Monasse, and P. Montmitonnet, Polym. Test., 6, 107 (1986)

17. R. J. Ion, M. Pollock, and C. Roques-Cames, J. Mater. Sci., 25, 1444 (1990).

18. Y. Deslandes, E. Alva Rosa, E. Brisse, and T. Meneghini, J. Mater. Sci., 26, 2769 (1991)

19. F. J. Baltá Calleja, Trends Polym. Sci., 2, 419 (1994).

20. F. J. Baltá Calleja, and S. Fakirov, Trends Polym. Sci., 5, 246 (1997).

21. C. Santa Cruz, F. J. Baltá Calleja, H. G. Zachmann, N. Stribeck, and T. Asano, J. Polym. Sci., Part B, Polym. Phys., 29, 819 (1991).

22. D. R. Rueda, A. Viksne, L. Malers, and F. J. Baltá Calleja, Macromol. Chem. Phys., 195, 3869 (1994).
23. Proc. NEDO International Symposium on Polymer Crystallization: "Fundamental Studies on Crystallization of Polymers," Kyoto, March 1998.

24. U. Köncke, H.G. Zachmann, and F. J. Baltá Calleja, Macromolecules, 29, 6019 (1996).

25. P. P. Huo and P. Cebe, Macromolecules, 25, 902 (1992).

26. Technical Data Sheet A-00, Mitsui Toatsu Chem., Inc., Tokyo, Japan.

27. A. P. Deshpande and J. C. Seferis, J. Thermoplastic Compos. Mat., submitted.

28. H. G. Zachmann and C. Wutz, in "Crystallization of Polymers," NATO ASI Series, M. Dosier, Ed., Kluwer Acad. Publishers, Dordrecht, 1993, p 403.

29. F. J. Baltá Calleja, J. Martinez de Salazar, and D. R. Rueda, Encycl. Polym. Sci. Eng., 7, 614 (1987).

30. F. J. Baltá Calleja, and H. G. Kilian, Coll. Polym. Sci., 266, 29 (1988).

31. F. J. Baltá Calleja, C. Santa Cruz, R. Bayer, and H. G. Kilian, Coll. Polym. Sci., 268, 440 (1990). 